Silvio Leone

Polis, Platz und Porträt 


\section{Urban Spaces}

Edited by

Susanne Muth, Jennifer Trimble and Ulrike Wulf-Rheidt (†)

Editorial Board

Franz Alto Bauer, Janet DeLaine, Steven Ellis, Lothar Haselberger, Adolf Hoffmann, Cornelia Jöchner, Katharina Lorenz, Carlos Noreña, Philipp von Rummel, Stephan Schmid

\section{Band 9}




\section{Silvio Leone}

\section{Polis, Platz und Porträt}

Die Bildnisstatuen auf der Agora von Athen im Späthellenismus und in der Kaiserzeit (86 v. Chr. -267 n. Chr.) 
Gedruckt mit freundlicher Unterstützung der Geschwister Boehringer Ingelheim Stiftung für Geisteswissenschaften in Ingelheim am Rhein.

ISBN 978-3-11-065283-3

e-ISBN (PDF) 978-3-11-061740-5

e-ISBN (EPUB) 978-3-11-061751-1

ISSN 2194-4857

Library of Congress Control Number: 2020934015

Bibliografische Information der Deutschen Nationalbibliothek

Die Deutsche Nationalbibliothek verzeichnet diese Publikation in der Deutschen Nationalbibliografie; detaillierte bibliografische Daten sind im Internet über http://dnb.dnb.de abrufbar.

(C) 2020 Walter de Gruyter GmbH, Berlin/Boston

Satz: Meta Systems Publishing \& Printservices GmbH, Wustermark

Umschlagabbildung: Athen, Agora, Rekonstruktion (Zeichnung nach H. A. Thompson) @ akg-images, AKG431207

Druck und Bindung: Hubert \& Co. GmbH Co. KG, Göttingen

www.degruyter.com 
Ai miei genitori 
